\title{
Crystal Structure and Magnetic Properties of an Asymmetrical Dinuclear Mn(III) Complex with $N$-(2-Oxymethylphenyl)salicylideneimine
}

\author{
Yuki Suemitsu, Ko Yoneda, Yasunori Yamada, and Masayuki KoIKaWA ${ }^{\dagger}$ \\ Department of Chemistry and Applied Chemistry, Faculty of Science and Engineering, Saga University, 1 Honjo, \\ Saga, Saga 840-8502, Japan
}

\begin{abstract}
An asymmetric dinuclear $\mathrm{Mn}(\mathrm{III})$ complex, $\left[\mathrm{Mn}_{2}(\mathrm{~L} 1-\mathrm{H})_{2}(\mathrm{OBz}) \mathrm{Cl}\left(\mathrm{H}_{2} \mathrm{O}\right)\right] \cdot \mathrm{CH}_{3} \mathrm{CN}\left[\mathrm{H}_{2} \mathrm{~L} 1-\mathrm{H}=\mathrm{N}\right.$ - $(2$-oxymethylphenyl)salicylideneimine], was synthesized and characterized by single-crystal $\mathrm{X}$-ray analysis. The compound crystallizes in the triclinic space group $P \overline{1}$ with $a=10.9807(15), b=12.3290(17), c=14.492(2) \AA, \alpha=80.004(10), \beta=74.181(8)$, $\gamma=64.614(7)^{\circ}, V=1701.8(4) \AA^{3}, D_{\text {calcd }}=1.514 \mathrm{~g} / \mathrm{cm}^{3}, Z=2$. The $R 1[I>2 \sigma(I)]$ and $w R 2$ (all data) values are 0.0376 and 0.0999 , respectively, for all 5382 independent reflections. The complex has a bis- $\mu$-alkoxo bridged dinuclear structure with a syn-syn bridged benzoate as an axial ligand. Magnetic measurements of $\mathbf{1}$ indicate that a weak antiferromagnetic interaction is operative in the dimanganese core with $J$ value of $-12.6 \mathrm{~cm}^{-1}$.
\end{abstract}

(Received April 6, 2018; Accepted May 7, 2018; Published on web July 10, 2018)

Tridentate ligands containing hydroxyl groups at both peripheral positions of the ligand framework easily formed bis- $\mu$-alkoxo/ phenoxo bridged dinuclear structures. ${ }^{1,2}$ We are interested in the syntheses of metal complexes with such tridentate ligands, and have reported on the bis- $\mu$-alkoxo bridged dinuclear complexes with $O N O$ donor ligands. ${ }^{3,4}$ To extend the series of our research, we report on the crystal structure of a bis- $\mu$-alkoxo dinuclear manganese(III) complex, $\left[\mathrm{Mn}_{2}(\mathrm{~L} 1-\mathrm{H})_{2}(\mathrm{OBz}) \mathrm{Cl}\left(\mathrm{H}_{2} \mathrm{O}\right)\right] \cdot \mathrm{CH}_{3} \mathrm{CN}$ (1), with an additional syn-syn benzoate bridge.

The ligand $\mathrm{H}_{2} \mathrm{~L} 1-\mathrm{H}$ was obtained by a literature method. ${ }^{5}$ A mixture of $\mathrm{H}_{2} \mathrm{~L} 1-\mathrm{H}(0.113 \mathrm{~g}, 0.5 \mathrm{mmol})$, manganese chloride tetrahydrate $(0.100 \mathrm{~g}, 0.5 \mathrm{mmol})$, and sodium benzoate $(0.073 \mathrm{~g}$, $0.5 \mathrm{mmol})$ in dry acetonitrile solution $(20 \mathrm{~mL})$ was refluxed for $30 \mathrm{~min}$. The obtained greenish brown solution was filtered, and left under an open atmosphere to evaporate the solvent slowly. Dark-green crystals suitable for $\mathrm{X}$-ray analysis were obtained after 3 days. $\left[\mathrm{Mn}_{2}(\mathrm{~L} 1-\mathrm{H})_{2}(\mathrm{OBz}) \mathrm{Cl}\left(\mathrm{H}_{2} \mathrm{O}\right)\right]$ (Yield $0.037 \mathrm{~g}, 9.53 \%$ ). $\mathrm{C}_{37} \mathrm{H}_{32} \mathrm{ClMn}_{2} \mathrm{~N}_{3} \mathrm{O}_{7}$ (776.00).

$\mathrm{X}$-Ray diffraction measurements were made on a Rigaku VariMax Saturn CCD 724+ diffractometer with graphite monochromated Mo $K \alpha$ radiation at $113 \mathrm{~K}$. The structure was solved by direct methods (SIR92) and expanded using Fourier techniques. The non-hydrogen atoms were refined

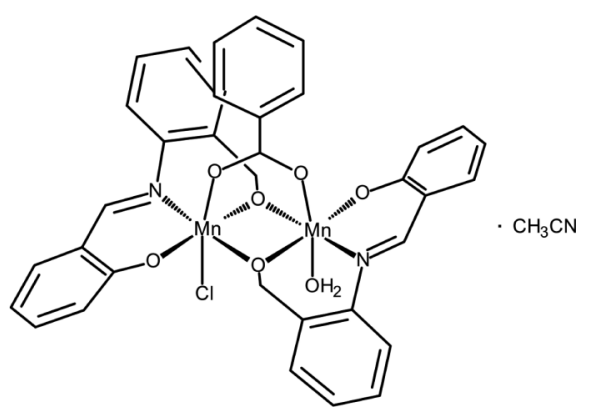

Fig. 1 Chemical structure of complex 1.

† To whom correspondence should be addressed.

E-mail: koikawa@cc.saga-u.ac.jp anisotropically. Hydrogen atoms (H38A and H38B) involved in hydrogen bonds were located in difference Fourier maps, and refined using the riding model. $\mathrm{O}-\mathrm{H}$ distances associated with $\mathrm{H} 38 \mathrm{~A}$ and $\mathrm{H} 38 \mathrm{~B}$ were restrained to ensure a reasonable distance [O7-H38A = 0.86 $\AA$, O7-H38B = 0.88 ] by applying an $\mathrm{O}-\mathrm{H}$ DFIX restraint (SHELXL2016) of $0.90(2) \AA ̊ .6$ Other hydrogen atoms were located on the calculated positions, and refined using the riding model. The final cycle of full-matrix leastsquares refinement on $F^{2}$ using SHELXL2016/6 was based on observed reflections and variable parameters, and converged with unweighted and weighted agreement factors of $R$ and $R_{\mathrm{w}} \cdot{ }^{6}$ Details of the X-ray structure determination are listed in Table 1.

Table 1 Crystal and experimental data

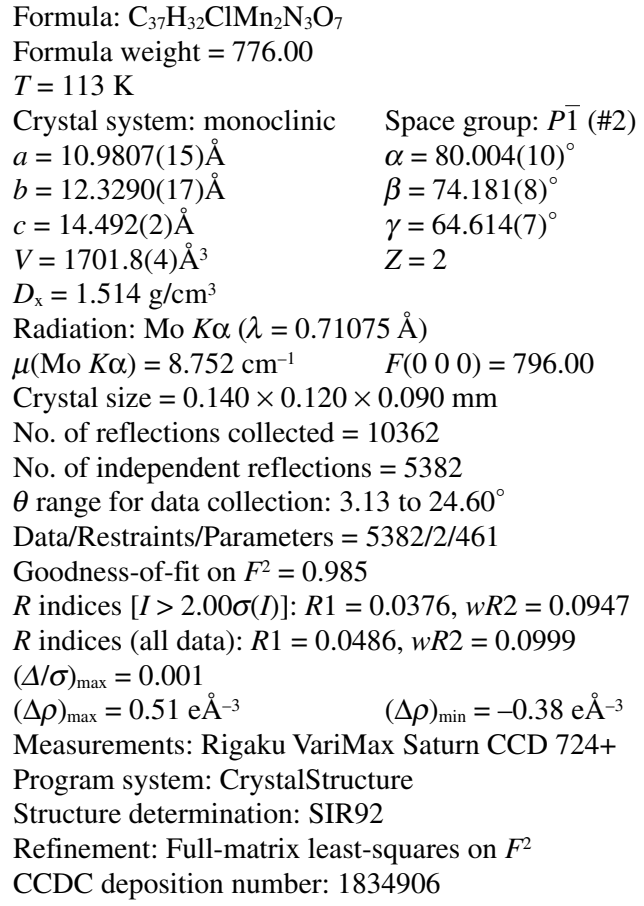




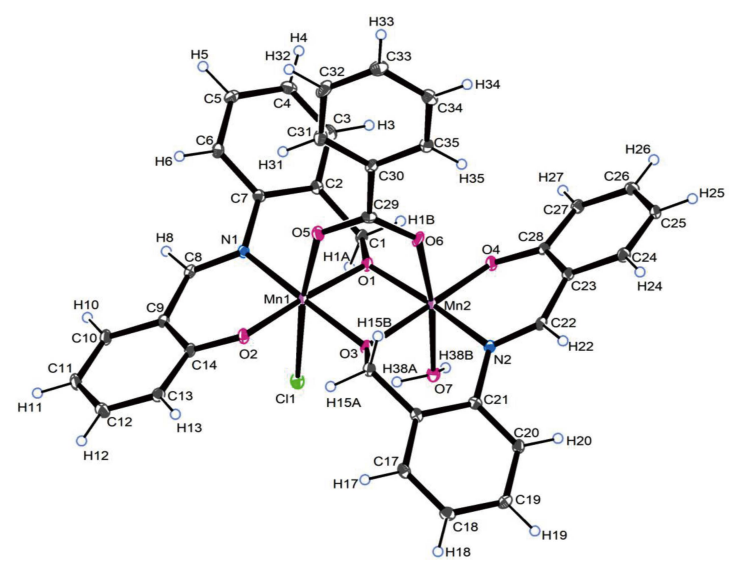

Fig. 2 ORTEP drawing for $\mathbf{1}$ with the atom-numbering scheme. Displacement ellipsoids are drawn at the $50 \%$ probability level.

Table 2 Selected bond lengths $(\AA)$ and angles $\left({ }^{\circ}\right)$ of 1

\begin{tabular}{lclr}
\hline Mn1-N1 & $2.016(3)$ & $\mathrm{Mn} 2-\mathrm{N} 2$ & $2.023(3)$ \\
$\mathrm{Mn} 1-\mathrm{O} 1$ & $1.8949(16)$ & $\mathrm{Mn} 2-\mathrm{O} 1$ & $1.965(3)$ \\
$\mathrm{Mn} 1-\mathrm{O} 2$ & $1.8576(15)$ & $\mathrm{Mn} 2-\mathrm{O} 3$ & $1.9179(16)$ \\
$\mathrm{Mn} 1-\mathrm{O} 3$ & $1.962(3)$ & $\mathrm{Mn} 2-\mathrm{O} 4$ & $1.8462(15)$ \\
$\mathrm{Mn} 1-\mathrm{O} 5$ & $2.1648(19)$ & $\mathrm{Mn} 2-\mathrm{O} 6$ & $2.1624(18)$ \\
$\mathrm{Mn} 1-\mathrm{Cl} 1$ & $2.6911(9)$ & $\mathrm{Mn} 2-\mathrm{O} 7$ & $2.230(2)$ \\
$\mathrm{Mn} 1 \cdots \mathrm{Mn} 2$ & $2.9263(8)$ & & \\
Cl1-Mn1-O5 & $173.11(6)$ & O1-Mn2-O3 & $80.77(9)$ \\
O1-Mn1-O2 & $175.76(11)$ & O1-Mn2-O4 & $95.20(9)$ \\
O1-Mn1-O3 & $81.44(9)$ & O1-Mn2-N2 & $171.40(7)$ \\
O1-Mn1-N1 & $91.80(9)$ & O3-Mn2-O4 & $173.82(9)$ \\
O2-Mn1-O3 & $94.33(9)$ & O3-Mn2-N2 & $91.80(9)$ \\
O2-Mn1-N1 & $92.42(9)$ & O4-Mn2-N2 & $92.55(9)$ \\
O3-Mn1-N1 & $170.22(8)$ & O6-Mn2-O7 & $172.36(8)$ \\
Mn1-O1-Mn2 & $98.59(9)$ & Mn1-O3-Mn2 & $97.92(9)$ \\
\hline
\end{tabular}

An ORTEP drawing of $\mathbf{1}$ is shown in Fig. 2, and the selected bond lengths and angles are listed in Table 2. The complex has a bis- $\mu$-alkoxo- $\mu$-carboxylato triply bridged dimanganese(III) structure. An equatorial dinuclear plane, defined by a $\left[\mathrm{Mn}_{2}(\mathrm{~L} 1-\mathrm{H})_{2}\right]$ unit, formed nearly coplanar. The bond distances between $\mathrm{Mn}$ atom and donor atoms of $(\mathrm{L} 1-\mathrm{H})^{2-}$ are in the range of $1.8462(15)-2.023(3) \AA$. For axial positions, a benzoate anion coordinates to two Mn atoms as a syn-syn carboxylato bridge. The remaining axial positions of $\mathrm{Mn} 1$ and $\mathrm{Mn} 2$ are occupied by $\mathrm{Cl}^{-}$and $\mathrm{H}_{2} \mathrm{O}$ to give an asymmetrical dinuclear

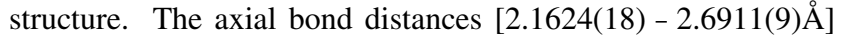
are longer than the equatorial distances due to typical JahnTeller distortion for Mn(III) ions. The coordination geometries for $\mathrm{Mn} 1$ and $\mathrm{Mn} 2$ are considered to be in an elongated octahedral environment. The intramolecular $\mathrm{Mn} 1 \cdots \mathrm{Mn} 2$ distance is 2.9263(8) $\AA$. The distance is close to those of similar syn-syn carboxylato bridged dimanganese(III) complexes. ${ }^{7,8}$ Furthermore, the distance of $\mathbf{1}$ is between $\left[\mathrm{Mn}_{2}{ }_{2}(\mathrm{salpa})_{2} \mathrm{Cl}_{2}\left(\mathrm{H}_{2} \mathrm{O}\right)_{2}\right] ; 3.001(1) \AA$ and $\left[\mathrm{Mn}_{2}{ }_{2}(\operatorname{salpa})_{2}(\mu-\mathrm{AcO})_{2}\right] ; 2.869(1) \AA\left[\mathrm{H}_{2}\right.$ salpa $=1$ - $($ salicylaldeneamino)-3-hydroxypropane]. ${ }^{1,9}$ Figure 3 is a molecular packing diagram of $\mathbf{1}$. The coordinating water $(\mathrm{O} 7$ and $\mathrm{H} 38 \mathrm{~B})$ is hydrogen-bonded to the $\mathrm{Cl} 1^{\mathrm{i}}$ [Symmetry code (i): $2-x, 1-y$, $-z$ ] in 3.145(2) $\AA$ distance $\left(\mathrm{O} 7-\mathrm{H} 38 \mathrm{~B} \cdots \mathrm{Cl} 1^{\mathrm{i}}\right)$. Finally, 1 forms dimer-of-dimers by these intermolecular hydrogen bonds.

Figure $\mathrm{S} 1$ shows the temperature dependence of the magnetic susceptibilities $\left(\chi_{\mathrm{A}}\right)$ and the magnetic moment $\left(\mu_{\text {eff }}\right.$, for 1 . The magnetic moment at $300 \mathrm{~K}$ of $4.16 \mathrm{~B} . \mathrm{M}$. is slightly smaller than

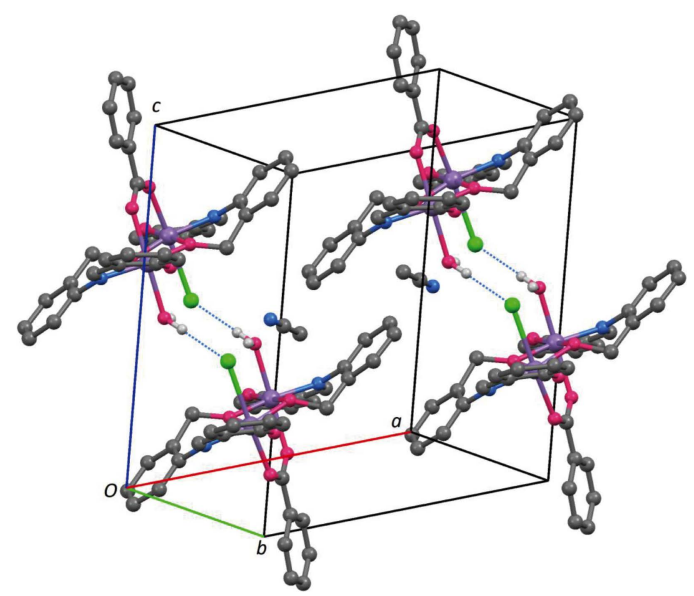

Fig. 3 Molecular packing diagram of $\mathbf{1}$. Hydrogen bonds are represented as dashed lines. $\mathrm{H}$ atoms, except for the coordinating $\mathrm{H}_{2} \mathrm{O}$, have been omitted for clarity.

the spin-only value for a magnetically isolated $\mathrm{Mn}(\mathrm{III})$ ion. The moments decrease monotonically from $300 \mathrm{~K}$ to 0.305 B.M. at $2.0 \mathrm{~K}$. This behavior indicates that an antiferromagnetic interaction exists between two manganese(III) ions. The magnetic analysis was carried out using a theoretical equation derived from the Heisenberg model spin-exchange Hamiltonian $\left(H=-2 J S_{1} S_{2}, S_{1}=S_{2}=2\right)$. The correction term for monomeric $\mathrm{Mn}$ (III) species is applied to the equation. The best-fitting parameters obtained by a least-squares procedure are $J=$ $-12.6 \mathrm{~cm}^{-1}, g=1.96$. Many dinuclear Mn(III) complexes with one syn-syn carboxylato bridge also exhibit a similar trend $\left(\left[\mathrm{Mn}_{2} \mathrm{~L}^{1}(\mu\right.\right.$-AcO $)(\mu$-MeO $\left.)(\text { methanol })_{2}\right] \mathrm{Br}\left(\mathrm{H}_{3} \mathrm{~L}^{1}=1,5\right.$-bis(2-hydroxybenzophenylideneamino)pentan-3-ol); $J=-13.1 \mathrm{~cm}^{-1}, g=1.90$, $\left[\mathrm{Mn}_{2}\left(\mathrm{~L}^{2}\right)(\mu-\mathrm{MeO})(\mu-\mathrm{AcO})(\mathrm{MeOH})_{2}\right] \mathrm{I}_{3}\left(\mathrm{H}_{3} \mathrm{~L}^{2}=1,5\right.$-bis(2-hydroxynaphtylideneamino)pentan-3-ol); $\left.J=-12.4 \mathrm{~cm}^{-1}, g=1.98\right){ }^{7,8}$

This work was supported by JSPS KAKENHI Grant Number JP26410075 from Japan Society for the Promotion of Science.

\section{Supporting Information}

A CIF format file and Fig. S1. These materials are available free of charge on the Web at http://www.jsac.or.jp/xraystruct/.

\section{References}

1. C. Zhang, J. Sun, X. Kong, and C. Zhao, J. Chem. Cryst., 1999, 29, 203.

2. M. Mitra, A. K. Maji, B. K. Ghosh, G. Kaur, A. R. Choudhury, C. Lin, J. Ribas, and R. Ghosh, Polyhedron., 2013, 61, 15.

3. M. Koikawa, H. Yamashita, and T. Tokii, Inorg. Chem. Commun., 2003, 6, 157.

4. M. Koikawa, K. Iwashita, and T. Tokii, Acta Cryst., 2004, E60, m239.

5. M. Nath and R. Yadav, Synth. React. Met.-Org. Chem., 1995, 25(9), 1529.

6. G. M. Sheldrick, SHELX2016/6, Acta Cryst., 2008, A64, 112.

7. V. Daier, H. Biava, C. Palopoli, S. Shova, J. P. Tuchagues, and S. Signorella, J. Inorg. Biochem., 2004, 98, 1806.

8. H. Biava, C. Palopoli, S. Shova, M. D. Gaudio, V. Daier, M. G. Sierra, J. P. Tuchagues, and S. Signorella, J. Inorg. Biochem., 2006, 100, 1660.

9. M. Mikuriya, N. Torihara, H. Okawa, and S. Kida, Bull. Chem. Soc. Jpn., 1981, 54, 1063. 